\title{
Entrevista com o artista Fernando Velázquez
}

\section{Interview with the artist Fernando Velázquez}

\section{Sandra Conceição Nunes}

Doutoranda em Artes Visuais pela Universidade do Estado de Santa Catarina (Udesc) - sandranunes.arte@gmail.com - http://orcid.org/0000-0002-0002-0322

\section{Resumo}

Na entrevista, o artista uruguaio Fernando Vélazquez fala sobre o início de sua carreira, artistas que o influenciaram e como se tornou uma referência no uso da tecnologia em seus trabalhos, que utilizam suportes e formatos diversificados, além de abordar o uso da tecnologia na arte contemporânea. Vive em São Paulo/SP, desde o início da década de 2000 e participou de diversas exposições no Brasil e no exterior, atuando também como curador.

Palavras-chave: Entrevista. Arte e tecnologia. Arte contemporânea.

\begin{abstract}
In the interview, Uruguayan artist Fernando Vélazquez talks about the beginning of his career, artists who influenced him and how he became a reference in the use of technology in his works, which use diverse formats and supports, as well as addressing the use of technology in art. Contemporary Lives in São Paulo/SP, since the early 2000, and participated in several exhibitions in Brazil and abroad, also acting as curator.
\end{abstract}

Keywords: Interview. Art and technology. Contemporary art.

Recebido em: 29/10/2018

Aceito em: 19/11/2018 


\section{INTRODUÇÃO}

Fernando Velázquez concedeu a presente entrevista em dezembro de 2016, por correspondência eletrônica, com o objetivo de refletir sobre sua produção artística e o uso de tecnologias na arte. Utilizando suportes e formatos diversos - vídeos, instalações, performances audiovisuais, objetos interativos, imagens geradas com recursos algorítmicos - Fernando Velázquez se consolidou no cenário artístico com obras que discutem questões da contemporaneidade, como: a tecnologia e o comportamento humano, a relação entre arte e outras áreas do conhecimento, buscando construir processos e metodologias híbridas. O artista investiga as capacidades perceptivas do corpo humano e a mediação da realidade pelos dispositivos técnicos. É curador, desenvolve pesquisas na área do cinema expandido, arte algorítmica, hacktivismo e artivismo (VELÁZQUEZ, 2016).

Uruguaio, de Montevidéu, Fernando Velázquez adotou o Brasil para viver, e reside em São Paulo/SP desde 2001. Com uma ampla formação e bagagem artística, Velázquez é uma referência no uso da tecnologia e na utilização de diferentes mídias no campo das artes. Ele é Mestre em Moda, Arte e Cultura pela Faculdade Senac de Moda de São Paulo e especialista em Vídeo e Tecnologias Digitais on-line e off-line, pelo Mecad, de Barcelona. Também possui formação na área do Design, e teve passagem pela European Mobile Lab for Interactive Media Artists, da Universidade de Atenas (Grécia), Universidade de Artes Aplicadas de Viena (Áustria), Universidade de Lapland (Finlândia) e Faculdade de Arquitetura de Montevidéu (Uruguai) (VELAZQUEZ, [2016?]).

De sua vasta produção, podemos citar a série "Mindscapes", composta por vídeos, imagens algorítmicas, instalação e performance audiovisual, na qual o artista explora a visualidade e a atividade cerebral, resultando em infinitas composições - formas, cores, texturas e volumes criados por meio da atividade mental (neuroimagens). Destaca-se ainda "Paisagem Discreta", apresentada como uma possibilidade de interação entre público e obra. Utilizando webcam e microfone, o artista registra o que acontece em tempo real na sala expositiva. Também se distingue "Your life, our movie", um filme coletivo, criado em tempo real a partir da participação do público com uso da base de imagens do Flickr. Ao digitar palavras-chave em uma interface on-line, o sujeito ativa uma programação que procura imagens relacionadas (VELAZQUEZ, [2016?]).

Dentre as diversas exposições individuais e coletivas que participou no Brasil e no exterior, estão: Overview (Holanda, 2016), Visiones Sonoras (México, 2014), Emoção Art.ficial, Bienal de Arte 
e Tecnologia (Brasil, 2012), Bienal de Cerveira (Portugal, 2013 e 2011), Mapping Festival (Suiça, 2011), WRO Biennale (Polônia 2011), Bienal do Mercosul (Brasil, 2009), o Pocket Film Festival, no Centro Pompidou (França, 2007). O artista desenvolve trabalhos curatoriais para o Red Bull Station ${ }^{1}$ (São Paulo) desde 2015, organiza projetos e exposições como Projeto! wr? (2013), Papermind Brasil (2009) e Motomix (2007). Pela intensa produção, Fernando Velázquez foi agraciado com diversos prêmios, dentre eles: o Prêmio PROAC Livro de Artista (Brasil, 2013), Sergio Motta de Arte e Tecnologia (Brasil, 2009), Mídias Locativas Arte.Mov (Brasil, 2008), Festival Internacional de Mídias Móveis (Brasil, 2008) e o Vida Artificial (Espanha, 2008) (VELAZQUEZ, [2016?]).

\section{ENTREVISTA}

a. Sei que você vem do desenho e da pintura. Como foi o início de sua carreira artística? Quando passou a utilizar a tecnologia em suas obras e como se deu o processo de transição?

Fernando Velázquez: Venho da pintura e do desenho. No começo, na primeira década de 2000, comecei a experimentar com instalação, vídeo e também com a internet. Foi em 2003, ao entrar no curso de graduação em Design de Multimeios do Senac-SP, que minha produção adentra definitivamente no entorno digital. Naquele tempo havia uma efervescência a respeito do estudo das novas mídias e o Senac era uma das instituições relacionadas a esse movimento.

b. Quais são suas referências artísticas? De que forma elas influenciaram sua carreira, e em que momento isso é mais evidente?

Fui (e sou) muito influenciado por amigos e professores. Albano Afonso, Sandra Cinto, Lucia Leão, Luiz Duva, Lucas Bambozzi, Giselle Beiguelman, Julià Carboneras e Francisco Lapetina, são algumas das pessoas que formaram a minha personalidade artística. São pessoas que expandiram meus interesses e a minha pesquisa desde o ponto de vista ético, filosófico, estético, político e afetivo através do encontro e do diálogo.

\footnotetext{
${ }^{1}$ Espaço aberto em 2013, no centro de São Paulo, o qual ocupa a antiga subestação de energia Riachuelo, desativada em 2004. Oferece ações diversas e desenvolve projetos na área de música, arte multimídia e urban thinking. Possui programas permanentes de ocupação e residência artística. O Programa de Residência Artística estimula e apoia a formação e a produção de arte contemporânea e ocorre em duas edições anuais. A cada edição é lançado edital para selecionar seis artistas ou coletivos para receberem aporte financeiro e acompanhamento crítico de um curador e desenvolverem seus trabalhos, participarem de palestras, workshops, exposições, entre outras atividades (RED BULL STATION, [201-]).
} 
c. Você expôs em diferentes lugares do mundo e no Brasil. Como você vê a relação entre público e a arte tecnológica? Você identifica diferenças entre o público brasileiro e o público de outros países?

Tanto aqui como no exterior, a arte realizada com as tecnologias atuais vem se desenvolvendo principalmente em circuitos específicos como festivais ou exposições temáticas em instituições que já lidam com o tema. Diferenciaria dois tipos de públicos, sem importar o país: há o público já habituado a este tipo de trabalho, que consegue se relacionar com a obra de forma contextualizada em termos de técnicas e linguagens e há outro tipo de público, menos habituado, para o qual a tecnologia se apresenta de forma deslumbrante e rasa, o que diminui a densidade da potência artística.

\section{d. Qual a importância e influência do público em seu trabalho?}

Mais do que falar em público, prefiro me referir ao "outro". Acredito que quando uma obra apresenta uma determinada lógica, ela fica mais próxima do outro. Não se trata de reduzir para facilitar, e sim de oferecer caminhos para o diálogo com a proposição/obra.

e. Para você, qual o papel das tecnologias no processo de democratização e universalização da arte?

A tecnologia é uma ferramenta; a arte é uma equação aberta que envolve qualidades críticas, expressivas, técnicas e tecnológicas. A tecnologia pode aproximar repertórios e facilitar habilidades até pouco tempo atrás restritas ao campo da criação. Neste sentido, pode ser uma aliada na disseminação de conhecimento em torno do campo da arte, diminuindo brechas e criando repertório. Porém, pensemos que o pincel e a tinta estão ali ao alcance de todos há muito tempo, e nem por isso todos são artistas.

\section{f. Como você vê o mercado para a arte que usa a tecnologia na atualidade?}

O mercado é ainda incipiente, mas, na medida em que o descompasso entre as instituições culturais e este tipo de arte for diminuindo, e dada a exponencial diminuição do custo dos dispositivos tecnológicos, que por sua vez ficam cada vez mais estáveis, baratos e de fácil manutenção, o mercado rapidamente absorverá este tipo de produção.

g. Sobre as bienais de arte no Brasil, qual a importância delas para a produção em arte que utiliza as tecnologias?

Nenhuma. A Bienal de São Paulo parece desconhecer o assunto. 
Figura 1 - Acidente, Fernando Velázquez. 2011. Performance Audiovisual em tempo real.

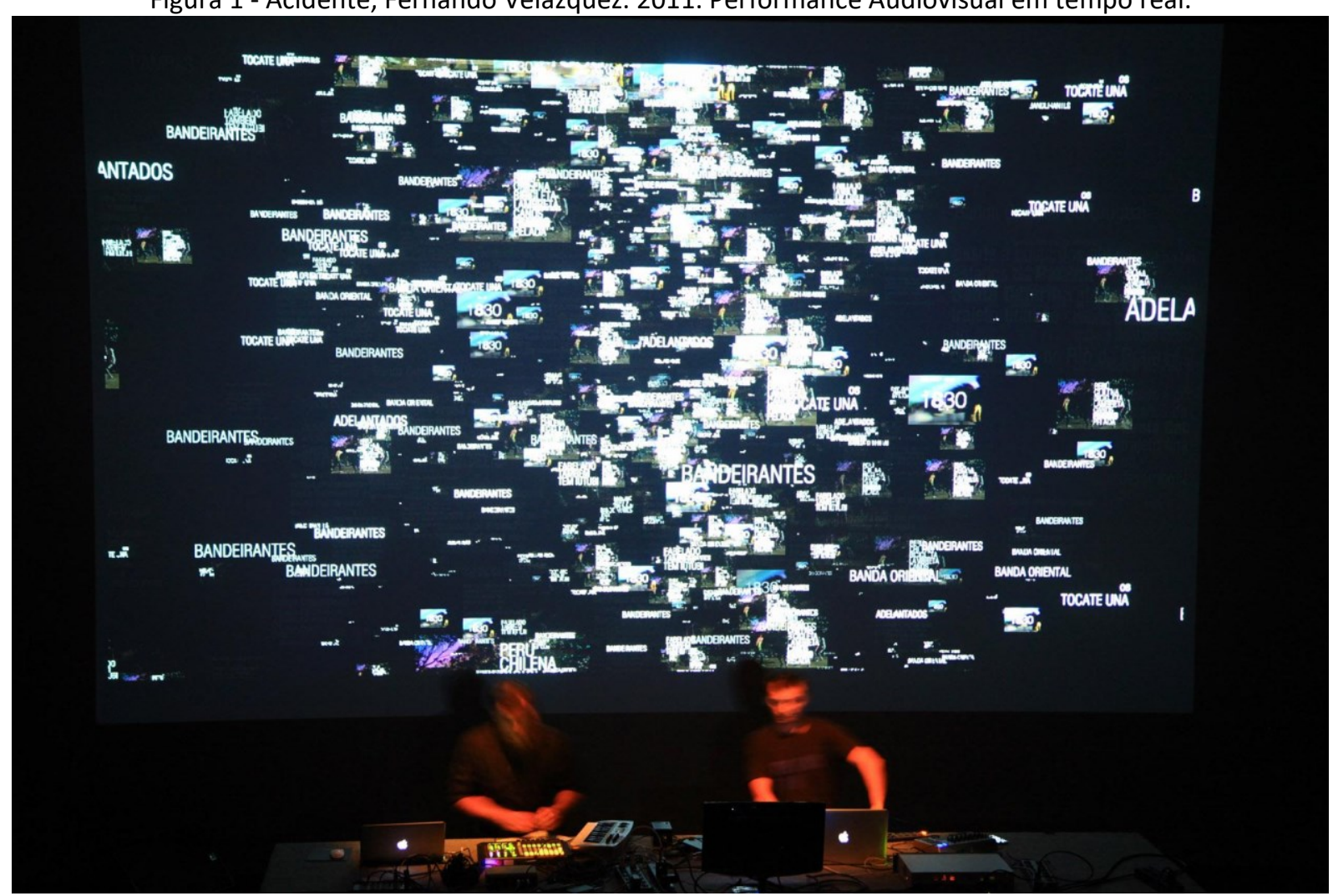

Fonte: Velázquez, [2016?].

h. Em "Acidente", uma performance audiovisual realizada em 2011, você apresenta relações entre sua terra natal (Uruguai) e o país que escolheu para viver (Brasil). Que aspectos você destaca sobre o processo e resultado da obra?

Neste projeto, havia uma hipótese inicial, a de que os pampas (Uruguai, Argentina e Brasil) são uma grande extensão de território com um imaginário e uma cultura em comum. A fronteira (limites geográficos) poderia ser entendida como um acidente, mais do que a demarcação de diferenças. A pesquisa de campo deu subsídios audiovisuais para pensar uma narrativa experimental híbrida entre a performance ao vivo e o documental. Gosto muito do diálogo entre imagens sintéticas e fotografia e da trilha sonora que mistura os ritmos típicos do sul com outros ritmos da região. Tango com Samba, Samba com Zamba e Milonga etc.

i. Você disse, em uma entrevista em 2010, que a arte digital está trazendo um problema de discriminação para o artista que usa a tecnologia. Nos seis anos que se passaram, esse pensamento mudou? Por quê? 
Ainda persiste no circuito a falsa dicotomia entre arte contemporânea e a digital, o que segmenta e relega a produção atual a espaços distintos. A chamada arte digital continua com pouca ou nenhuma inserção institucional, embora o problema começa a ser percebido e demarcado como tal. Acredito que ainda falta muito para que o discurso adotado por certas instituições se transforme em prática, e as exposições, seleções, fundos etc., reflitam um equilíbrio na contemplação de projetos que se utilizam das tecnologias contemporâneas.

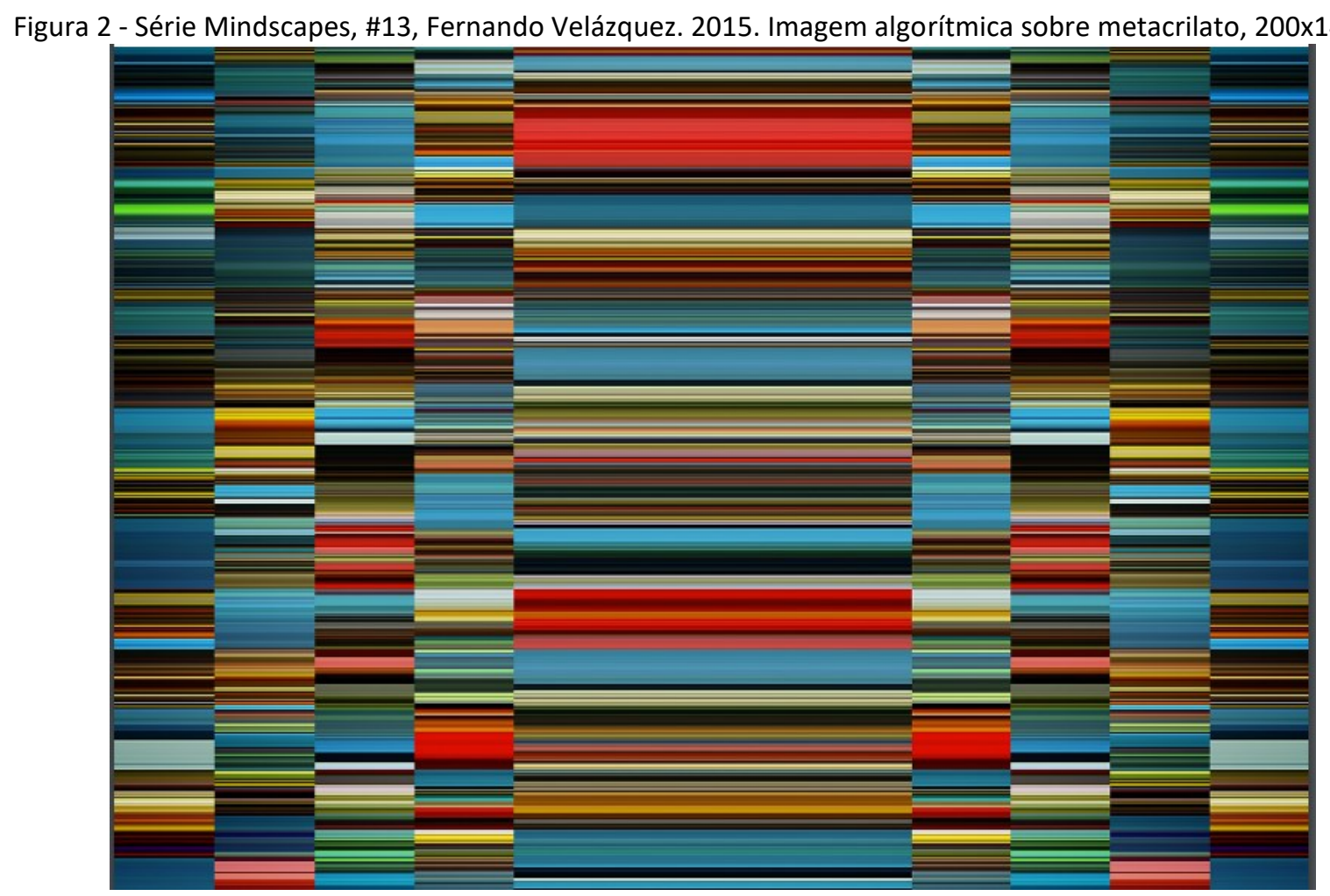

Fonte: Velázquez, [2016?].

j. Por favor, destaque os aspectos principais da série "Mindscapes", em que você explora a ideia de paisagem relacionada à atividade cerebral.

Na série Mindscapes, pesquiso uma visualidade para a atividade cerebral utilizando algoritmos generativos. Mindscapes é um projeto que inclui imagens algorítmicas, vídeo, instalação e performance audiovisual. Nesta série, busco explorar a ideia de paisagem relacionada à atividade cerebral, ao pensamento e ao imaginário, adentrando o terreno simbólico mais do que o dos fenômenos químico/biológicos. No lugar de traçar analogias com a realidade física da matéria, recorro a algoritmos generativos (redes neurais, por exemplo) para especular a respeito das 
estruturas, processos, fluxos e relacionamentos entre os diversos dispositivos e sistemas que nos conformam e influenciam o modo como percebemos o mundo, construímos o conhecimento e articulamos memórias. A série começou a ser desenvolvida em 2011, e desde então vem sendo ampliada sob diversas perspectivas, o que faz do projeto um engenho vivo e dinâmico em constante mutação.

Figura 3 - \#L1, after Dan Flavin, [da série Mindscapes], Fernando Velázquez. 2014. Instalação generativa. Dimensões variáveis. Computador, 16 barras de neon customizadas, 16 reatores, 4 rack de dmx, 4 alto-falantes, algoritmo personalizado.

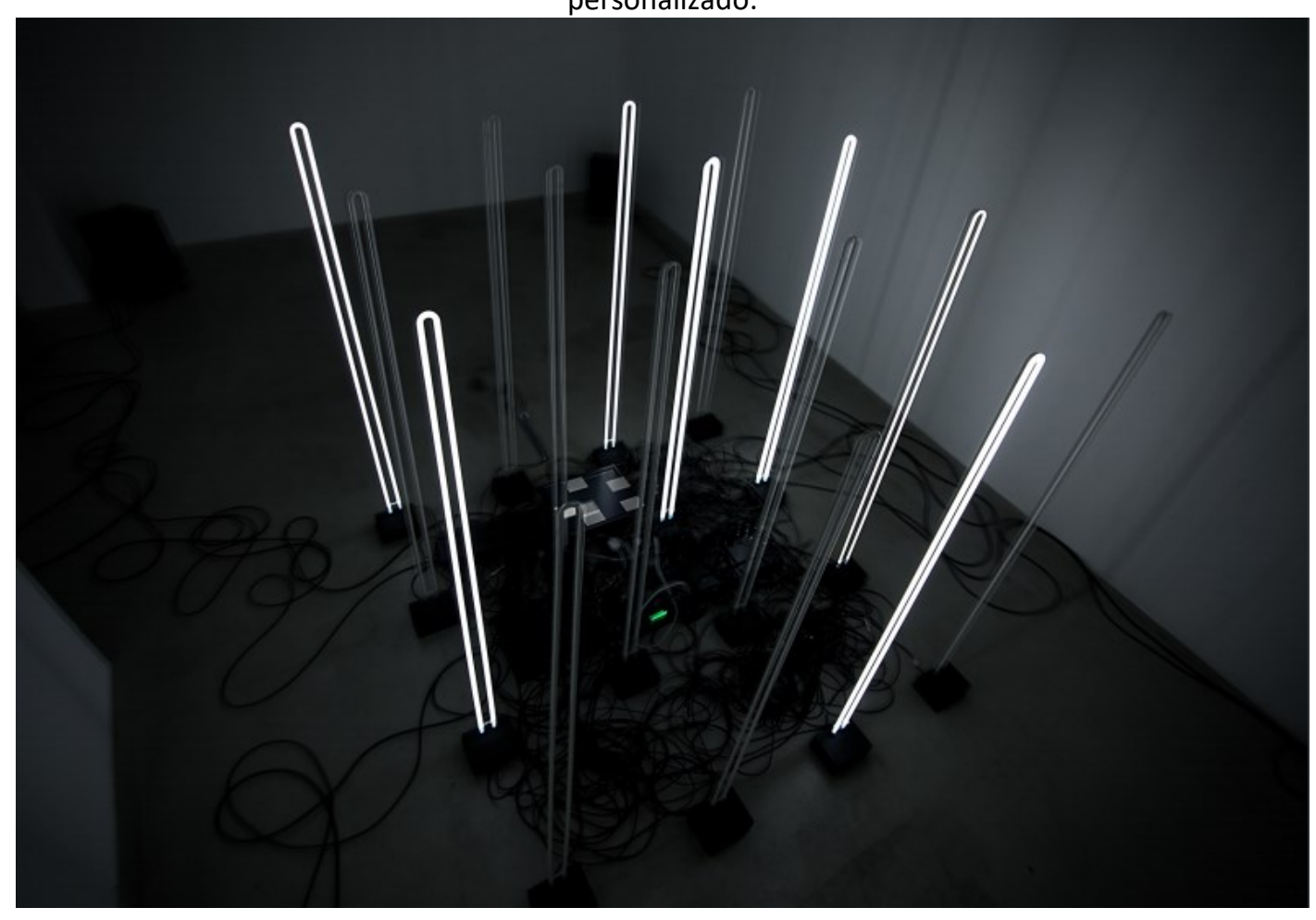

Fonte: Velázquez, [2016?].

k. Sobre sua experiência enquanto artista que realiza performances audiovisuais em tempo real, como você lida com a questão da imprevisibilidade?

As artes que transcorrem no tempo têm sempre, em maior ou menor medida, alguma relação com o imprevisto. No meu trabalho como performer audiovisual, o imprevisto é um elemento fundamental. Caso contrário, elas seriam formalizadas como uma obra fechada, um vídeo, por exemplo. Gosto de trabalhar as performances com partituras, isso quer dizer que parte dos acontecimentos responde a um sistema, a um corpo de dados organizados previamente, mas é o fato de performar que introduz, sobretudo no autor. 
I. A respeito da interação do espectador com a obra, de que maneira isto se insere em seu trabalho? Qual seu interesse enquanto artista?

Busco certa organicidade, procuro dar pistas de que há relações a serem construídas de maneira conjunta entre espectador e obra, mas procuro que isso se dê de maneira sutil.

m. Em suas obras, além da imagem visual você utiliza sons. Como se dá o processo de criação?

Me reconheço como artista visual, embora isso não diga muito, determina certa especificidade na matriz de pensamento. Gosto de pensar que trabalho o som como um artista visual. Nesse sentido, tento uma abordagem experimental longe dos cânones e das habilidades de um músico convencional que responde aos saberes próprios desta área do conhecimento.

Figura 4 - Retablo, Fernando Velázquez. 2016. Instalação interativa. Dimensões variáveis. Computador, 3 projetores, kinect, 4 alto-falantes, algoritmo personalizado.

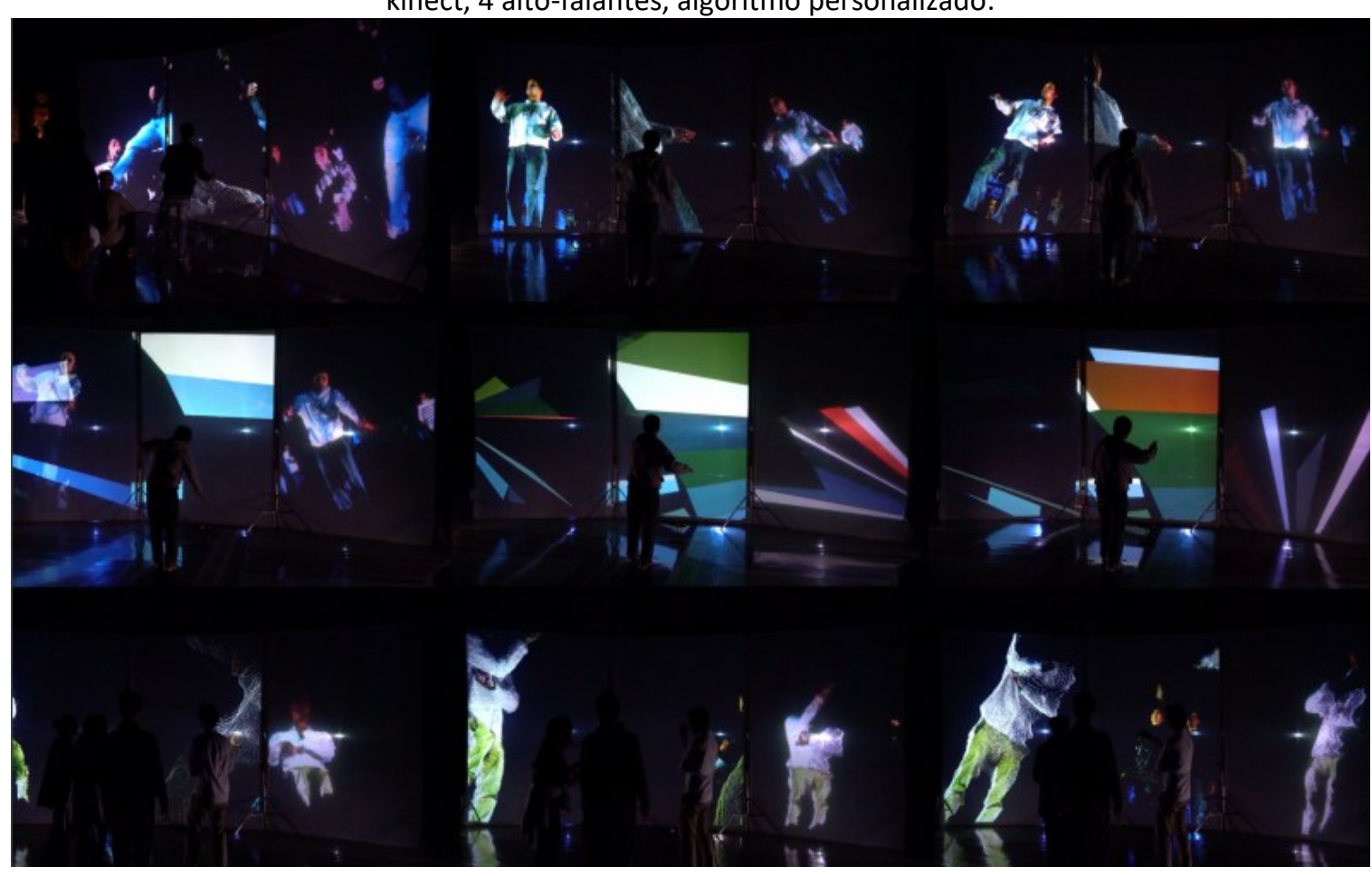

Fonte: Velázquez, [2016?].

\section{n. Como você vê a produção artística brasileira na área da arte e tecnologia?}

O Brasil esteve, desde sempre, relacionado com este tipo de produção. Já nos anos 60 e 70 as obras de Abraham Palatnik e Waldemar Cordeiro apontavam caminhos. Na década de 80, a USP 
teve uma grande importância tecendo redes com laboratórios e instituições, sobretudo da Europa. O trabalho de Gilberto Prado e Julio Plaza, entre muitos outros artistas e pesquisadores, se destaca neste período.

Com o auge do patrocínio cultural por empresas relacionadas à tecnologia e à expansão dos cursos acadêmicos, nos anos 2000, houve o crescimento e amadurecimento da produção local na obra de artistas como: Raquel Kogan, Lucas Bambozzi, Giselle Beiguelman e Rejane Cantoni, dentre outros artistas que têm conseguido reconhecimento internacional.

Acredito que nos últimos anos tem havido certa defasagem com respeito à produção de outros lugares, isso talvez seja fruto da diminuição do assunto nas pautas institucionais e nos departamentos de marketing das empresas.

\section{o. Por fim, que projetos de futuro se enunciam para seus trabalhos?}

Em 2016, desenvolvi a instalação interativa "Retablo", onde investigo o campo do retrato a partir das possibilidades técnicas do Kinect, que funciona, neste caso, como um scanner 3D em tempo real. A história da arte no século XX introduziu e desenvolveu a ideia de campo expandido, o que possibilitou a desmaterialização da arte com base em discursos metalinguísticos. Em "Retablo" a ideia central é a de dialogar com o campo da pintura e da escultura, introduzindo questões próprias do nosso tempo como a existência de um corpo de dados que, transitando em redes, pode ser entendido como uma prótese que media a nossa relação com o mundo. Em contrapartida, há meios como a pintura e a escultura convencionais de forte apelo material, a visualização digital do corpo coloca ênfase na estrutura imaterial, o corpo como informação. É possível assim escanear o corpo em tempo real e apresentá-lo desde os mais diversos ângulos, em movimento (mesmo que a matriz esteja em repouso), transformá-lo acrescentando dados inexistentes ou, simplesmente, reduzi-lo ao mínimo de informação inteligível. Para além das questões inerentes à representação, essa pesquisa também revela a condição específica do espaço/tempo contemporâneo, onde o cotidiano é continuamente mediado por dispositivos técnicos em rede e a subjetividade, consequentemente, distribuída por estes canais.

\section{REFERÊNCIAS}

RED BULL STATION. São Paulo, [201-]. Apresenta informações e programação no Red Bull Station, espaço cultural voltado para a arte contemporânea. Disponível em:

http://www.redbullstation.com.br. Acesso em: 15 nov. 2018. 
VELÁZQUEZ, Fernando. [Correspondência]. Destinatário: Sandra Conceição Nunes. Florianópolis, 14 dez. 2016. 1 correio eletrônico (e-mail).

VELÁZQUEZ, Fernando. [São Paulo], [2016?]. Mostra as produções do artista em diferentes mídias, além de textos e atividades desenvolvidas profissionalmente. Disponível em: www.blogart.com. Acesso em: 10 jan. 2017. 